\title{
Immunomodulation with Thymalin in the COVID-19 Re- lated Cytokine Storm: Case Reports
}

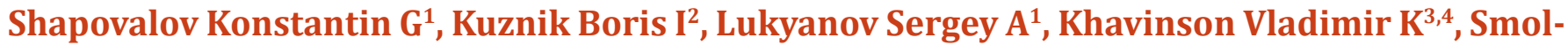 \\ yakov Yuri N ${ }^{1}$, Tereshkov Pavel $\mathbf{K}^{1}$, Shapovalov Yuri $\mathbf{K}^{1}$, Konnov Valery $\mathbf{A}^{1}$ and Magen Eli ${ }^{5 *}$ \\ ${ }^{1}$ Anesthesiology-resuscitation Department, Chita State Medical Academy, Russia
}

${ }^{2}$ Normal physiology Department, Chita Medical Academy, Russia

${ }^{3}$ Saint-Petersburg Institute of Bioregulation and Gerontology, St. Petersburg, Russian Federation, Russia

${ }^{4}$ IP Pavlov Institute of Physiology, St. Petersburg, Russian Federation, Russia

${ }^{5}$ Clinical Immunology and Allergy Division, Medicine C Department, Ben Gurion University of the Negev, Israel

*Corresponding author: Magen Eli, Clinical Immunology and Allergy Division, Medicine C Department, Ben Gurion University of Negev, Zionut 21/33, Ashdod, 77456, Israel.

To Cite This Article: Smolyakov Yuri N, Tereshkov Pavel K, Shapovalov Yuri K, Konnov Valery A, Magen Eli, Immunomodulation with Thymalin in the COVID-19 Related Cytokine Storm: Case Reports. 2020 - 10(6). AJBSR.MS.ID.001574. DOI: 10.34297/AJBSR.2020.10.001574.

Received: 啙 October 19, 2020; Published: 㘹 November 16, 2020

\begin{abstract}
Background: Immunosuppression and "Cytokine storm" in severe coronavirus disease (COVID-19) occur almost simultaneously. The elderly persons with COVID-19 are at high risk for uncontrolled cytokine storm and deep immunosuppression. Thymalin, polypeptide medication obtained from the calf thymus may be used in the treatment of severe COVID-19 patients, using immunomodulatory therapy.

Case presentation: Here we present two patients (the first a 72-year-old male and the second a 69-year-old female) with severe COVID-19 related bilateral pneumonia. In both cases we observed the increased levels of acute-phase reactants and an inflammatory biomarker profile with marked lymphopenia, therefore cytokine storm due to COVID-19 was diagnosed. Both patients were first treated with hydroxychloroquine, cefoperazone/sulbactam, and tocilizumab without any clinical benefit; and was then given thymalin treatment with impressive clinical and laboratory improvement. We performed immunophenotyping of peripheral blood mononuclear cells to assess the dynamics of these cells during COVID-19 related cytokine storm, tocilizumab, and thymalin administration. We observed a decline of CD4+, B-Lymphocytes, and NK-cells after tolicuzimab administration. CD8+ T-cell levels were negatively correlated with inflammatory indicators ESR, CRP, and IL-6.

Conclusions: Thymalin has a beneficial effect on severe COVID-19 related pneumonia and "cytokine storm". To get more evidence, a randomized, controlled trial of Thymalin in COVID-19 is being performed.

Keywords: Case; Report; Thymalin; Immunomodulation, COVID-19; Cytokine, Storm

Abbreviations: SARS-CoV-2: Severe Acute Respiratory Syndrome Coronavirus 2; COVID-19: Severe Coronavirus Disease 19; HIV: Human Immunodeficiency Virus; ARDS: Acute Respiratory Distress Syndrome; PEEP: Positive End-Expiratory Pressure; PCR: Polymerase Chain Reaction; Fi02: Fraction of Inspired Oxygen; MAS: Macrophage Activation Syndrome; HLH: Hemophagocytic Lymphohistiocytosis; CAR-T: Chimeric Antigen Receptor T Cells; PBMC: Peripheral Blood Mononuclear Cells
\end{abstract}

\section{Introduction}

Infection induced by a novel severe acute respiratory syndrome coronavirus 2 (SARS-CoV-2) coronavirus, named coronavirus diseases 19 (COVID-19), causes acute T cell exhaustion, which might lead to ineffective antiviral immunity [1]. Most COVID-19 cases demonstrated severe lymphocytopenia, especially in aged patients and severe cases [2]. Age is the strongest predictor of the severity and lethality of COVID-19 [3].

Two important immunological signs of aging are a fall of thymic $\mathrm{T}$ cell output and $\mathrm{T}$ cell diversity, that leads to a reduced capacity to mount strong adaptive immune responses to new antigens in 
later life [4]. Immunosuppression and "Cytokine storm" in severe COVID-19 occur almost simultaneously and have been widely recognized by clinicians, even so, they are not unique to COVID-19 and also occur in other respiratory viral infections [5,6]. The elderly persons are also at high risk for uncontrolled, over-inflammation reactions, and deep immunosuppression [7]. Therefore, it is important to suppress the disproportionate inflammatory response and repair the deep immunosuppression in the treatment of severe COVID-19 patients, using "immunomodulatory therapy".

Polypeptide medication thymalin obtained from the calf thymus is known to have immunomodulatory properties, enhancing Th1 cytokine production along with $\mathrm{T}$ cell differentiation and maturation, augmenting the involvement of a specific $\mathrm{T}$ helper cell response in antiviral defense [8]. Thymalin has been successfully used in clinical practice as an adjunct therapy in the treatment of patients infected with influenza, viral hepatitis B and C, herpes simplex and human immunodeficiency virus (HIV); moreover, several clinical studies demonstrated its beneficial effect in the treatment of severe sepsis and acute respiratory distress syndrome (ARDS) [9].

Here we present two patients with severe COVID-19 related bilateral pneumonia and the "Cytokine storm", who were first treated with hydroxychloroquine, cefoperazone/sulbactam, and tocilizumab without any clinical benefit; and was then given thymalin treatment with impressive clinical and laboratory improvement. Per institutional guidelines, the patients' consent was obtained before publishing these cases.

\section{Cases Presentation}

\section{Case 1}

A 72-year-old male patient with body mass index $27.4 \mathrm{~kg} / \mathrm{m} 2$ was admitted to the intensive care unit (ICU) isolation ward of Chita District Hospital (Chita, Russia). He had reportedly tested positive for COVID-19 before arrival at our hospital. On hospital admission, the patient was hypoxic and tachypneic. Arterial blood gas analysis after admission revealed a pH of 7.41, PCO2 of 32, PO2 of 44.9, and $\mathrm{SaO} 2$ of $88 \%$. A chest X-ray revealed bilateral hazy opacities, thus suggesting possible multifocal pneumonia or pulmonary edema due to ARDS. Transthoracic echocardiography revealed normal values of echocardiographic measurements. The infectious workup, including blood and urine cultures, nasopharyngeal swab PCR testing for influenza (A and B), and respiratory syncytial virus, Legionella urinary antigen were negative. Laboratory results revealed elevated acute phase reactants and lymphopenia and eosinopenia (Table 1). The increased levels of acute-phase reactants, an inflammatory biomarker profile, and profound lymphopenia supported our suspicion of cytokine storm due to COVID-19 [10]. The treatment included mechanical ventilation, hydroxychloroquine, cefoperazone/ sulbactam, levofloxacin, and heparin. Additionally, the patient received two doses of tocilizumab (Actemra) at $400 \mathrm{mg}$ administered $12 \mathrm{~h}$ apart. On day 6, the patient experienced progressively worsening hypoxemic respiratory failure. He required a 100\% fraction of inspired oxygen (FiO2) and positive end-expiratory pressure (PEEP) of $12 \mathrm{~cm} \mathrm{H2O}$ to maintain an oxygen saturation of $>90 \%$. He was managed by intermittent prone positioning, fluid restriction, and mechanical ventilation. Laboratory studies revealed a further rising in serum inflammatory markers and a depression of cellular immunity (Table 1).

The first CT scan showed a large area of ground-glass opacity with irregular density in the subpleural regions of both lungs, with 'crazy-paving sign, predominantly in the lower lobes; on day six, multiple patchy consolidations were apparent in both lungs, with air bronchus-charging sign and thickening of the pulmonary interstitium surrounding the lesions (Figure 1). Because of a lack of tocilizumab efficacy, on day 6 in ICU, the decision was made to discontinue the current medications and to treat the patient with thymalin 10 mg daily intramuscularly injections for 10 days. Within 48 hours of receiving thymalin, the patient showed marked clinical improvement. He had a significant decrease in oxygen requirements and her laboratory inflammatory markers showed a descending trend (Table 1). On day 23 in ICU hospitalization, the patient was weaned to the standard nasal cannula. He was consequently discharged from the hospital without supplemental oxygen when follow-up COVID-19 PCR testing was negative.

Table 1: $\mathrm{O}_{2}$ requirements, hematological parameters and acute phase reactants during hospitalization in ICU Male, white, 70 years.

\begin{tabular}{|c|c|c|c|c|}
\hline & \begin{tabular}{lr} 
Day 1 & 04.07 .2020 \\
Transfer to ICU & Start \\
Tocilizumab & Continue \\
+ & Hydroxichloro- \\
quin & + Cefoperazone $/$ \\
sulbactam & + \\
\multicolumn{3}{c}{ Levofloxacin }
\end{tabular} & 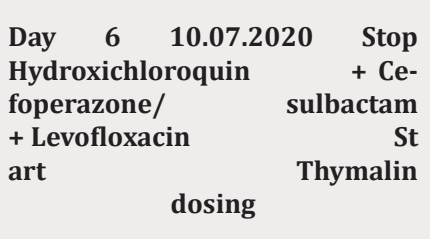 & 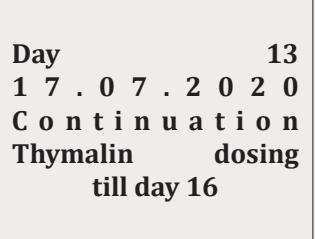 & Day 23 27.07.2020 Quit ICU \\
\hline $\mathrm{O}_{2}(\mathrm{~L} / \mathrm{min})$ & 5 & - & - & 3 \\
\hline PEEP, $\mathrm{cm} \mathrm{H}_{2} \mathrm{O}$ & 5 & 16 & 8 & - \\
\hline $\mathrm{FiO} 2(\%)$ & $40 \%$ & $100 \%$ & $60 \%$ & $30 \%$ \\
\hline $\mathrm{PaO} 2, \mathrm{~mm} \mathrm{Hg}$ & 44.9 & 49.7 & 147 & 113 \\
\hline
\end{tabular}




\begin{tabular}{|c|c|c|c|c|}
\hline $\begin{array}{l}\text { Sp02 (on room } \\
\text { air) }\end{array}$ & $86 \%$ & $88 \%$ & $95 \%$ & $93 \%$ \\
\hline $\begin{array}{l}\text { WBC (cells x } \\
10^{\wedge} 9 / \mathrm{L} \text { ) }\end{array}$ & 7.24 & 7.1 & 11.4 & 8.53 \\
\hline $\begin{array}{c}\text { Neutrophils } \\
\text { (cells } \times 10^{\wedge} 9 / \mathrm{L} \text { ) }\end{array}$ & 5.97 & 6.67 & 9.23 & 5.58 \\
\hline $\begin{array}{l}\text { Lymphocytes } \\
\text { (cells x } 10^{\wedge} 9 / \mathrm{L} \text { ) }\end{array}$ & 0.76 & 0.56 & 1.14 & 1.42 \\
\hline $\begin{array}{c}\text { Eosinophils (cells } \\
\times 10^{\wedge} 9 / \mathrm{L} \text { ) }\end{array}$ & 0.01 & 0.37 & 0.3 & 0.57 \\
\hline $\begin{array}{c}\text { Platelets (cells x } \\
10^{\wedge} 9 / \mathrm{L} \text { ) }\end{array}$ & 159 & 206 & 246 & 296 \\
\hline CRP (mg/L) & 48.0 & 92.5 & 12 & 15.5 \\
\hline LDH (U/L) & 470.9 & 1240.4 & 807.8 & 356 \\
\hline D-dimer (ng/mL) & 5000 & 9500 & 1250 & - \\
\hline $\begin{array}{c}\text { Fibrinogen D } \\
(\mathrm{g} / \mathrm{L})\end{array}$ & 11.5 & 6.8 & 7.1 & 6.1 \\
\hline $\begin{array}{c}\text { Fibrinogen } \\
\text { Clauss (g/L) }\end{array}$ & 3.7 & 3.6 & 4.1 & 3.9 \\
\hline $\begin{array}{l}\text { Prothrombin } \\
\text { time }(\mathrm{s})\end{array}$ & 12.9 & 13.8 & 13.2 & 12.7 \\
\hline $\begin{array}{l}\text { Procalcitonin } \\
\text { (ng/mL) }\end{array}$ & $<0.5$ & 0,75 & - & - \\
\hline $\begin{array}{c}\text { Neutrophils/ } \\
\text { Lymphocytes } \\
\text { ratio }\end{array}$ & 7.85 & 11.91 & 8.09 & 3.92 \\
\hline $\begin{array}{l}\text { Lymphocytes/ } \\
\text { Monocytes ratio }\end{array}$ & 1.55 & 2 & 1.65 & 1.35 \\
\hline $\begin{array}{l}\text { Platelets/ Leuko- } \\
\text { cytes ratio }\end{array}$ & 21.96 & 29.01 & 21.57 & 34.7 \\
\hline iL-6 (pg/ml) & 105.3 & 137 & 25.5 & - \\
\hline $\begin{array}{l}\text { Total T-Iympho- } \\
\text { cytes (cells/ } \mu \mathrm{L} \text { ) }\end{array}$ & 364 & 375 & 478 & - \\
\hline CD4+ (cells $/ \mu \mathrm{L})$ & 222 & 121 & 274 & - \\
\hline CD8+ (cells/ $\mu \mathrm{L})$ & 157 & 270 & 231 & - \\
\hline CD4/CD8 ratio & 1.41 & 0,448 & 1,18 & - \\
\hline $\begin{array}{c}\text { CD3+HLA-DR+ } \\
\text { (cells/ } \mu \mathrm{L})\end{array}$ & 26 & 77 & 88 & - \\
\hline $\begin{array}{l}\text { Total B-Iympho- } \\
\text { cytes (cells/ } \mu \mathrm{L} \text { ) }\end{array}$ & 129 & 74 & 147 & - \\
\hline $\begin{array}{l}\text { NK-cells (cells/ } \\
\mu \mathrm{L} \text { ) }\end{array}$ & 380 & 42 & 302 & - \\
\hline $\begin{array}{c}\text { NKT cells (cells/ } \\
\mu \mathrm{L} \text { ) }\end{array}$ & 74 & 33 & 30 & - \\
\hline $\begin{array}{l}\text { WBC-platelet ag- } \\
\text { gregates (cells/ } \\
\mu \mathrm{L} \text { ) }\end{array}$ & 3352 & 3287 & 5166 & - \\
\hline $\begin{array}{l}\text { Lympho- } \\
\text { cyte-platelet } \\
\text { aggregates } \\
\text { (cells/ } \mu \mathrm{L} \text { ) }\end{array}$ & 132 & 56 & 215 & - \\
\hline $\begin{array}{l}\text { Monocyte-plate- } \\
\text { let aggregates } \\
\text { (cells } / \mu \mathrm{L} \text { ) }\end{array}$ & 611 & 270 & 660 & - \\
\hline
\end{tabular}




\begin{tabular}{|c|c|c|c|c|}
\hline $\begin{array}{c}\text { Neutrophil- } \\
\text { ic-platelet aggre- } \\
\text { gates (cells/ } \mu \mathrm{L} \text { ) }\end{array}$ & 2386 & 2723 & 3980 & - \\
\hline $\begin{array}{c}\text { T-lympho- } \\
\text { cyte-platelet } \\
\begin{array}{c}\text { aggregates } \\
\text { (cells/ } \mu \mathrm{L} \text { ) }\end{array}\end{array}$ & 26 & 28 & 55 & - \\
\hline
\end{tabular}

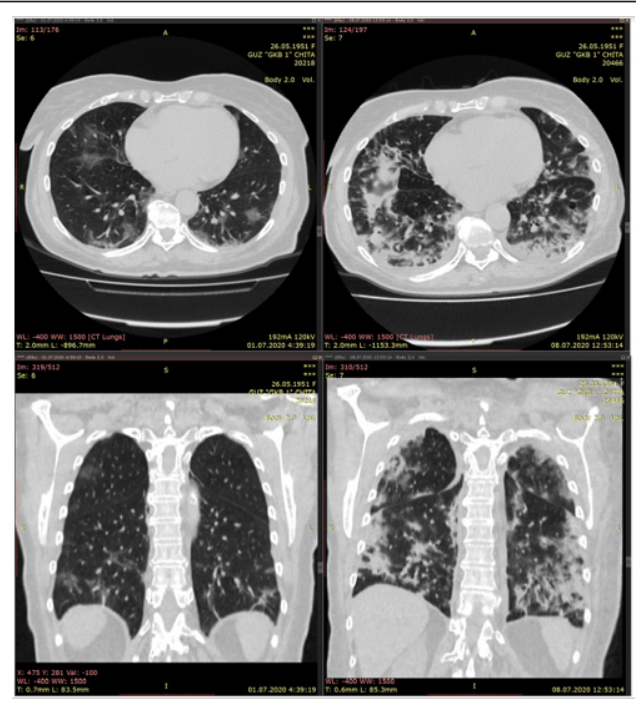

Figure 1: The first CT scan showed a large area of ground-glass opacity with irregular density in the subpleural regions of both lungs, with 'crazypaving sign, predominantly in the lower lobes; on day six, multiple patchy consolidations were apparent in both lungs, with air bronchus-charging sign and thickening of the pulmonary interstitium surrounding the lesions.

\section{Case 2}

A 69-year-old female was admitted to the Chita District Hospital (Chita, Russia) due to worsening respiratory failure and fever. The patient had other comorbid diseases including hypertension for 15 years, coronary heart disease for 5 years, and type two diabetes mellitus for 9 years. The pharyngeal swab RT-PCR test for COVID-2019 was positive. At admission, blood pressure of 145/84 $\mathrm{mmHg}$, and pulse of 94 beats per minute and respiratory rate was 32 per minute. The oxygen saturation values were decreased to as low as $88 \%$ and $\mathrm{PaO} 2$ was $66.2 \mathrm{mmHg}$. Due to critically severe type COVID-19, the patient was transmitted to the ICU.
As in the previous case, we observed the increased levels of acute-phase reactants and an inflammatory biomarker profile with marked lymphopenia, therefore cytokine storm due to COVID-19 was diagnosed (Table 2). The patient was treated with hydroxychloroquine, intravenous injections of hydroxychloroquine, cefoperazone/sulbactam, levofloxacin, and heparin. The patient also received three doses of tocilizumab (Actemra) at $400 \mathrm{mg}$. On day 3 , the patient was on mechanical ventilation due to hypoxemic respiratory failure, but further worsened lymphopenia, thrombocytopenia, elevated CRP levels, and developed hemodynamic instability, requiring vasopressor support by intravenous noradrenaline.

Table 2: $\mathrm{O}_{2}$ requirements, hematological parameters and acute phase reactants during hospitalization in ICU Female, white, 69 years.

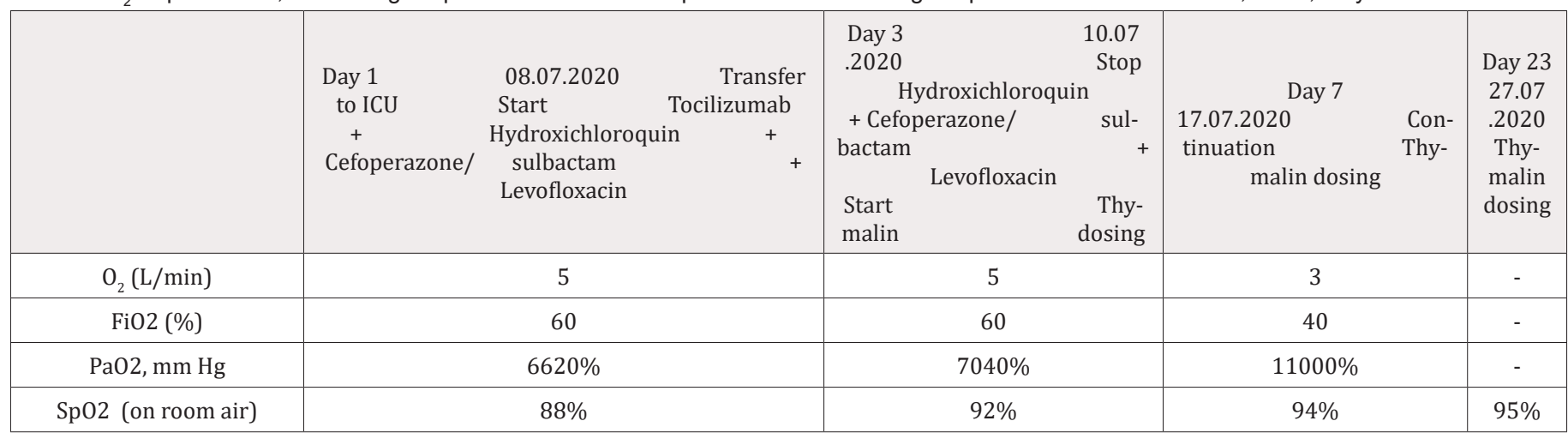




\begin{tabular}{|c|c|c|c|c|}
\hline WBC (cells $\left.\times 10^{\wedge} 9 / \mathrm{L}\right)$ & $896 \%$ & $795 \%$ & $1232 \%$ & $599 \%$ \\
\hline $\begin{array}{c}\text { Neutrophils (cells } x \\
10^{\wedge} 9 / \mathrm{L} \text { ) }\end{array}$ & 6.85 & 6.62 & 9.28 & 3.51 \\
\hline $\begin{array}{c}\text { Lymphocytes (cells x } \\
10^{\wedge} 9 / \mathrm{L} \text { ) }\end{array}$ & 0.8 & 0.66 & 1.45 & 1.62 \\
\hline $\begin{array}{c}\text { Eosinophils (cells x } \\
10^{\wedge} 9 / \mathrm{L} \text { ) }\end{array}$ & 0.01 & 0.02 & 0.03 & 0.03 \\
\hline Platelets (cells x 10^9/L) & 272 & 100 & 409 & 269 \\
\hline CRP (mg/L) & 62.2 & 96 & 44,4 & 6,0 \\
\hline LDH (U/L) & 804.7 & 603.3 & 378.8 & - \\
\hline D-dimer (ng/mL) & 1500 & 750 & - & 700 \\
\hline Fibrinogen D (g/L) & 10,5 & 11.1 & 6.9 & 6.6 \\
\hline Fibrinogen Clauss (g/L) & 3,5 & 2,0 & 3,2 & 3,0 \\
\hline Prothrombin time (s) & 12.6 & 14.2 & 12.9 & 12.2 \\
\hline Procalcitonin (ng/mL) & 0.5 & - & - & - \\
\hline $\begin{array}{l}\text { Neutrophils/ Lympho- } \\
\text { cytes ratio }\end{array}$ & 8.56 & 10.03 & 6.4 & 2.16 \\
\hline $\begin{array}{l}\text { Lymphocytes/ Monocytes } \\
\text { ratio }\end{array}$ & 1.02 & 1.06 & 1.68 & 2.1 \\
\hline $\begin{array}{l}\text { Platelets/ Leukocytes } \\
\text { ratio }\end{array}$ & 30.35 & 1257 & 3319 & 449 \\
\hline iL-6 (pg/ml) & 174.8 & 60.16 & - & - \\
\hline $\begin{array}{l}\text { Total T-Iymphocytes } \\
\text { (cells } / \mu \mathrm{L} \text { ) }\end{array}$ & 400 & 424 & 532 & - \\
\hline CD $4+($ cells $/ \mu \mathrm{L})$ & 302 & 279 & 359 & - \\
\hline CD8+ (cells $/ \mu \mathrm{L})$ & 107 & 153 & 185 & - \\
\hline CD4/CD8 ratio & 2.82 & 1.82 & 1.94 & - \\
\hline CD3+HLA-DR+ $($ cells $/ \mu \mathrm{L})$ & 46 & 7 & 18 & - \\
\hline $\begin{array}{l}\text { Total B-lympho- } \\
\text { cytes (cells/ } \mu \mathrm{L} \text { ) }\end{array}$ & 36 & 82 & 94 & - \\
\hline NK-cells (cells/ $\mu \mathrm{L}$ ) & 90 & 91 & 60 & - \\
\hline NKT cells (cells/ $\mu \mathrm{L}$ ) & 15 & 92 & 68 & - \\
\hline $\begin{array}{l}\text { WBC-platelet aggregates } \\
\text { (cells } / \mu \mathrm{L} \text { ) }\end{array}$ & 6640 & 3727 & 7331 & - \\
\hline $\begin{array}{l}\text { Lymphocyte-platelet } \\
\text { aggregates (cells } / \mu \mathrm{L} \text { ) }\end{array}$ & 88 & 66 & 71 & - \\
\hline $\begin{array}{l}\text { Monocyte-platelet aggre- } \\
\text { gates }(\text { cells } / \mu \mathrm{L})\end{array}$ & 554 & 509 & 1254 & - \\
\hline $\begin{array}{l}\text { Neutrophilic-platelet } \\
\text { aggregates (cells } / \mu \mathrm{L} \text { ) }\end{array}$ & 5582 & 2958 & 6363 & - \\
\hline $\begin{array}{l}\text { T-lymphocyte-platelet } \\
\text { aggregates (cells } / \mu \mathrm{L} \text { ) }\end{array}$ & 37 & 22 & 21 & - \\
\hline
\end{tabular}

Chest CT clearly showed evidence of bilateral pneumonia and ground-glass opacity (Figure 2). Due to high fevers, the patient received antipyretic therapy. We considered the ongoing antibiotic treatment with hydroxychloroquine and tocilizumab to be ineffective, and this drug combination was discontinued. Instead, the patient started thymalin $10 \mathrm{mg}$ daily intramuscularly injections for 10 days. Within 96 hours of receiving thymalin, the patient be- came hemodynamically stable and showed marked improvement of respiratory failure. Her laboratory inflammatory markers also showed an improving tendency (Table 2). Subsequently, the patient was weaned to the standard nasal cannula and discharged from the hospital without supplemental oxygen and a negative COVID-19 PCR testing. 

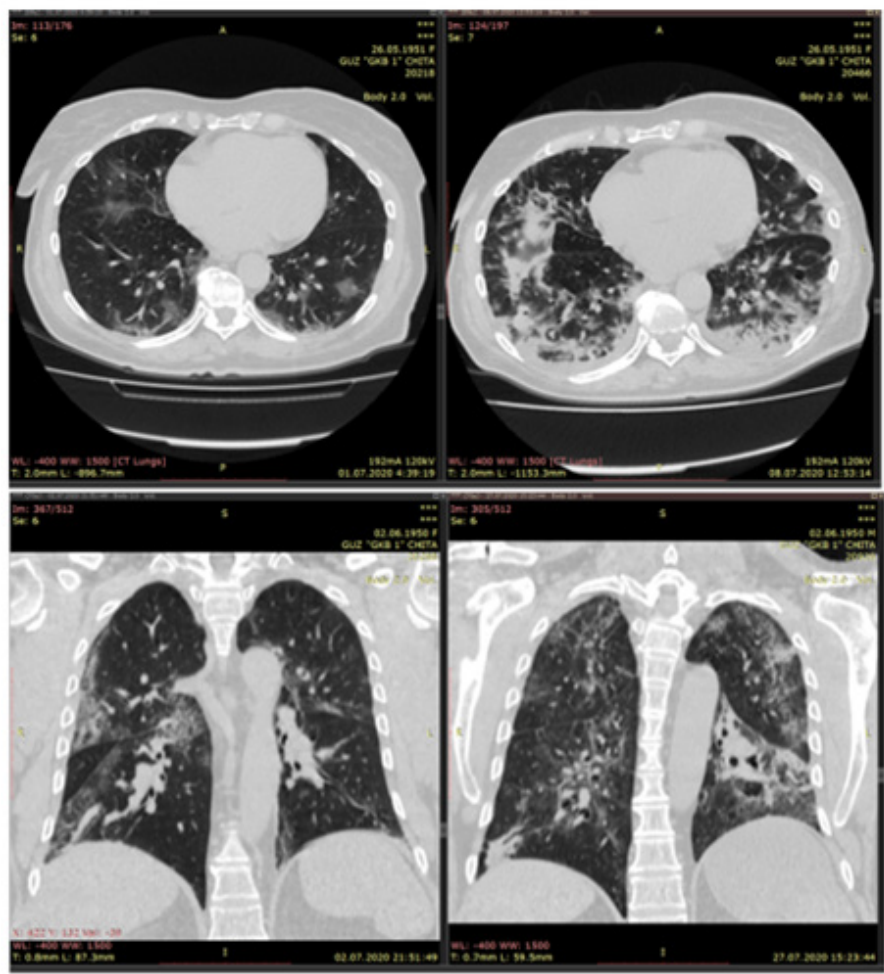

Figure 2: The first chest CT scan clearly showed evidence of bilateral pneumonia and ground-glass opacity; The seond CT scan on day 3 shows news multiple consolidations in both lungs, with air bronchus-charging sign and thickening of the pulmonary interstitium surrounding the lesions.

\section{Discussion}

In the presented case we observed that thymalin has a beneficial effect on severe COVID-19 related pneumonia and cytokine storm. Impairment of cell-mediated adaptive immunity is very common in COVID-19 patients, and most critically ill cases manifest severe lymphocytopenia [11]. In a recent retrospective study, Liu Y et al. reported that the Thymosin alpha 1 (T 1 1) supplement significantly reduces the mortality of severe COVID-19 patients [12]. The authors showed that T $\alpha 1$ effectively and quickly augments T cell counts in COVID-19 patients with severe lymphocytopenia, particularly in cases with the counts of CD8+ or CD4+ T cells lower than $400 / \mu \mathrm{L}$ or $650 / \mu \mathrm{L}$, respectively [12].

The inflammatory cytokine storm observed in COVID-19 shares features with macrophage activation syndrome (MAS) and hemophagocytic lymphohistiocytosis (HLH) but has some distinguishing characteristics [13]. The clinical features of patients with COVID-19 also parallel those in cytokine release syndrome, which arise as a result of CAR-T cell therapies [14]. The typical clinical picture of a patient with the cytokine storm includes rapid respiratory deterioration [15]. Our patients began to clinically decline and revealed symptoms of progressive respiratory failure on the first day of admission. In both patients the onset of the cytokine storm was evidenced by increased levels of acute-phase markers (D-di- mer, CRP, LDH, ferritin, Il-6), low platelets, decreased fibrinogen, lymphopenia, coagulopathy, and lung tissue damage. Lymphopenia is a frequently reported feature of COVID-19 induced cytokine storm and lymphopenia with leukocytosis may serve a key feature in the differential diagnosis of severe COVID-19 [16]. As the activation of IL- 6 is thought to be the key feature of the progression of COVID-19 pneumonia to ARDS and cytokine storm pathophysiology, IL-6 receptor inhibition has promise as a therapeutic strategy [17]. Accordingly, on day 1 of admission, we started an intravenous administration of tocilizumab $400 \mathrm{mg}$ for the treatment for COVID-19 induced cytokine release syndrome. In our patient, tocilizumab was administered in combination with ongoing hydroxychloroquine and antibiotics on day 1 , followed by subsequent doses 12 hours apart. Our patients did not show any clinical improvement after tocilizumab administration, although we administered multiple doses of the drug. In an observational study, Giamarellos-Bourboulis et al. administered tocilizumab to six patients and observed that the absolute lymphocyte levels in the six patients decreased after this therapy [18]. Interestingly, we also observed a decline of CD4+, B-Lymphocytes, and NK-cells after tolicuzimab administration. Whether this decline is related to the cytokine storm-related immunosuppression on to tocilizumab treatment, is unknown. The earliest reports of patient outcomes after treatment with tocilizumab for COVID-19 were very small, heterogeneous, and uncontrolled. 
Recent observational and randomized studies in hospitalized patients with COVID-19 provide evidence that supports both potential benefit and lack of benefit from tocilizumab treatment $[19,20]$.

In our cases, we performed immunophenotyping of peripheral blood mononuclear cells (PBMC) to assess the dynamics of these cells during COVID-19 related cytokine storm, tocilizumab, and thymalin administration. As CD8+ T-cell levels are negatively correlated with inflammatory indicators ESR, CRP, and IL-6, these cells might be a potential predictor for disease severity and clinical efficacy in COVID19 infection [21]. Moreover, flow cytometry analysis of PBMC phenotype may help predict the risk of clinical progression of the COVID-19 and more effective adaptive immune responses [22]. WBC-platelet aggregates have been described as an important factor in the pathogenesis of and the adhesion of platelets to leukocytes is a marker of platelet activation and leukocyte function [23]. We measured the amount of WBC-platelet aggregates in the peripheral blood of our patients, including granulocyte, monocyte, and lymphocyte aggregates by a flow cytometric method. Possibly, the observed reinstatement of WBC-platelet aggregates in the peripheral blood after thymalin administration reflects the restoration of WBC function and their activation in the recovery phase.

Lastly, observational and pathological studies in patients with COVID-19 have linked the cytokine storm with a pro-coagulant, thrombotic milieu $[24,25]$. Previous studies showed a beneficial effect of thymalin on blood coagulation and vasomotor function, especially when it was co-administered with heparin [26]. As COVID-19 infection is associated with coagulopathy from disseminated intravascular coagulation and thrombotic microangiopathy in its early stages; we consider thymalin to be an adjunct to anticoagulant therapy and thromboprophylaxis in patients with COVID-19 pneumonia. Even if our observations show an impressive efficacy of thymalin in COVID-19 related cytokine storm, a major limitation the case reports is a possible bias of open clinical observations.

\section{Conclusion}

Thymalin has a beneficial effect on severe COVID-19 related pneumonia and "cytokine storm". To get more evidence, a randomized, controlled trial of Thymalin in COVID-19 is being performed.

\section{Acknowledgements}

Not Applicable

\section{Conflict of Interest}

None to declare

\section{References}

1. Diao B, Wang C, Tan Y, Chen X, Liu Y, et al. (2020) Reduction and Functional Exhaustion of T Cells in Patients with Coronavirus Disease 2019 (COVID-19). Front Immunol 11: 827.

2. Chen R, Sang L, Jiang M, Yang Z, Jia N, et al. (2020) Medical Treatment Expert Group for COVID-19. Longitudinal hematologic and immunologic variations associated with the progression of COVID-19 patients in China. J Allergy Clin Immunol 6749(20) 30638-2.

3. Mueller AL, McNamara MS, Sinclair DA (2020) Why does COVID-19 disproportionately affect older people? Aging (Albany NY). 12(10): 9959-9981.

4. Fahy GM, Brooke RT, Watson JP, Zinaida Good, Shreyas S Vasanawala, et al. (2019) Reversal of epigenetic aging and immunosenescent trends in humans. Aging Cell 18(6): e13028.

5. Boomer JS, To K, Chang KC, Osamu Takasu, Dale F Osborne, et al. (2011) Immunosuppression in patients who die of sepsis and multiple organ failure. JAMA 306(23): 2594-2605.

6. Spencer JV, Religa P, Lehmann MH (2020) Editorial: Cytokine-Mediated Organ Dysfunction and Tissue Damage Induced by Viruses. Front Immunol 11: 2 .

7. Liu Y, Mao B, Liang S, Jia-Wei Yang, Hai-Wen Lu, et al. (2020) Association between age and clinical characteristics and outcomes of COVID-19. Eur Respir J 55(5): 2001112.

8. MorozovVG, Khavinson VK (1997) Natural and synthetic thymic peptides as therapeutics for immune dysfunction. Int J Immunopharmacol 19(910): 501-505.

9. Saakov BA, Belovolova RA, Bakhutashvili VI (1987) Immunocorrective therapy of the traumatic syndrome. Biull Eksp Biol Med 104(7): 73-75.

10. Henry BM, de Oliveira MHS, Benoit S, Plebani M, Lippi G (2020) Hematologic, biochemical and immune biomarker abnormalities associated with severe illness and mortality in coronavirus disease 2019 (COVID-19): a meta-analysis. Clin Chem Lab Med 58(7): 1021-1028.

11. Yang X, Yu Y, Xu J, Huaqing Shu, Jia'an Xia, et al. (2020) Clinical course and outcomes of critically ill patients with SARS-CoV-2 pneumonia in Wuhan, China: a single-centered, retrospective, observational study. Lancet Respir Med 8(5): 475-481.

12. Liu Y, Pang Y, Hu Z, Ming Wu, Chenhui Wang, et al. (2020) Thymosin alpha $1(\mathrm{~T} \alpha 1)$ reduces the mortality of severe COVID-19 by restoration of lymphocytopenia and reversion of exhausted $\mathrm{T}$ cells. Clin Infect Disciaa 630.

13. McGonagle D, Sharif K, O'Regan A, Bridgewood C (2020) The Role of Cytokines including Interleukin-6 in COVID-19 induced Pneumonia and Macrophage Activation Syndrome-Like Disease. Autoimmun Rev 19(6): 102537.

14. Buonaguro FM, Puzanov I, Ascierto PA (2020) Anti-IL6R role in treatment of COVID-19-related ARDS. J Transl Med 18(1): 165.

15. Quirch M, Lee J, Rehman S (2020) Hazards of the cytokine storm and cytokine-targeted therapy in COVID-19 patients: A Review. J Med Internet Res 22(8): e20193.

16. Gattinoni L, Coppola S, Cressoni M, Busana M, Rossi S, et al. (2020) COVID-19 Does Not Lead to a "Typical" Acute Respiratory Distress Syndrome. Am J Respir Crit Care Med 201(10): 1299-1300.

17. Lipworth B, Chan R, Lipworth S, RuiWen Kuo C (2020) Weathering the Cytokine Storm in Susceptible Patients with Severe SARS-CoV-2 Infection. J Allergy Clin Immunol Pract 8(6): 1798-1801.

18. Giamarellos Bourboulis EJ, Netea MG, Rovina N, Karolina Akinosoglou, Anastasia Antoniadou, et al. (2020) Complex Immune Dysregulation in COVID-19 Patients with Severe Respiratory Failure. Cell Host Microbe 27(6): 992-1000.e3.

19. Cheng GS, Hill JA (2020) To Toci or Not to Toci for COVID-19: Is That Still the Question? [published online ahead of print, 2020 Jul 31]. Clin Infect Disciaa1133.

20. Somers EC, Eschenauer GA, Troost JP, Jonathan L Golob, Tejal N Gandhi, et al. (2020) Tocilizumab for treatment of mechanically ventilated 
patients with COVID-19 [published online ahead of print, 2020 Jul 11]. Clin Infect Dis pp. 954.

21. Wang F, Nie J, Wang H, Qiu Zhao, Yong Xiong, et al. (2020) Characteristics of Peripheral Lymphocyte Subset Alteration in COVID-19 Pneumonia. J Infect Dis 221(11): 1762-1769.

22. Moratto D, Chiarini M, Giustini V, Federico Serana, Paola Magro, et al. (2020) Flow Cytometry Identifies Risk Factors and Dynamic Changes in Patients with COVID-19. J Clin Immunol p. 1-4.

23. Ishikawa T, Shimizu M, Kohara S, Takizawa S, Kitagawa Y, Takagi S. Appearance of WBC-platelet complex in acute ischemic stroke, predominantly in atherothrombotic infarction. J Atheroscler Thromb 19(5): 494-501.
24. Tang N, Li D, Wang X, Ziyong Sun, et al. (2020) Abnormal coagulation parameters are associated with poor prognosis in patients with novel coronavirus pneumonia. Journal of Thrombosis and Haemostasis 18(4): 844-847.

25. Wang T, Chen R, Liu C, Wenhua Liang, Weijie Guan et al. (2020) Attention should be paid to venous thromboembolism prophylaxis in the management of COVID-19. Lancet Haematol 7(5): e362-e363.

26. Khavison VKh, Kuznik BI, Sturov VG, Gladkii PA (2020) Thymalin use for respiratory diseases. Application potential in COVID-19. (1): 1-10. 